\title{
Clinicopathologic correlations of renal microthrombosis and inflammatory markers in proliferative lupus nephritis
}

\author{
Elena Gonzalo', Oscar Toldos², María P Martínez-Vidal³, María C Ordoñez ${ }^{4}$ Begoña Santiago', \\ Antonio Fernández-Nebro ${ }^{4}$, Estíbaliz Loza ${ }^{5}$, Isabel García ${ }^{6}$, Myriam León ${ }^{6}$, José L Pablos ${ }^{1,3+}$ and María Galindo ${ }^{1,3^{*}+}$
}

\begin{abstract}
Introduction: Microthrombosis is often observed in lupus nephritis (LN) lesions, but its clinical significance is unknown. We evaluated the clinicopathologic correlations of renal microthrombosis and inflammatory markers in LN.

Methods: Kidney biopsies from 58 patients with systemic lupus erythematosus (SLE) proliferative nephritis were analyzed with immunohistochemistry (IHC) for intravascular platelet aggregates (CD61), macrophagic infiltration (CD68), and activated complement deposition (C4d). Clinical data at the time of kidney biopsy and follow-up were analyzed with regard to pathologic IHC data.

Results: Microthrombosis was present in $52 \%$ of the tissues. It was significantly more prevalent in patients with antiphospholipid antibodies (aPLS) (62\% versus $42 \%)$. The presence of microthrombosis significantly correlated with higher macrophagic infiltration. Macrophagic infiltration but not microthrombosis was significantly correlated with C4d deposition. Only macrophagic infiltration showed a correlation with SLE and renal activity (proteinuria and active sediment), whereas neither the presence of $\mathrm{CD} 1^{+}$microthrombi nor the extent of $\mathrm{C} 4 \mathrm{~d}$ deposition correlated with LN severity or outcome.
\end{abstract}

Conclusions: Microthrombosis is associated with higher macrophagic infiltration in LN but does not seem to increase independently the severity of renal damage. Macrophagic infiltration was the best marker of SLE and renal activity in this LN series.

\section{Introduction}

Lupus nephritis (LN) develops in $30 \%$ to $50 \%$ of patients with systemic lupus erythematosus (SLE) [1]. Standard clinical practice is to perform a renal biopsy if clinical or analytic parameters suggest renal involvement. Although some clinical variables, such as elevation of serum creatinine or persistent elevations of blood pressure, have prognostic value, histologic information obtained from biopsies continues to be indispensable for classification and outcome prediction $[2,3]$. Among local inflammatory markers, glomerular and interstitial macrophage accumulation is a feature of the most aggressive forms of human

\footnotetext{
* Correspondence: mgalindo@h12o.es

+ Contributed equally

'Instituto de Investigación Hospital 12 de Octubre (i+12), Avenida de Córdoba sn, 28041 Madrid, Spain

Full list of author information is available at the end of the article
}

glomerulonephritis [4]. These cells, together with dendritic cells, are the major source of inflammatory cytokines [5], and their interaction with resident $\mathrm{T}$ cells may amplify renal inflammation. Monocyte numbers in the urine and urinary levels of the monocyte chemoattractant protein-1 (MCP-1) have been found to be useful markers to monitor the activity of $\mathrm{LN}[6,7]$. In patients with proliferative forms of LN, MCP-1 also may play a role in modulating interstitial inflammatory cell infiltration and tubulointerstitial damage via the transforming growth factor (TGF)-beta 1 pathway [8]. Therefore, glomerular and tubular macrophagic infiltration has important pathogenetic implications, and it is one of the individual variables that best correlates with clinical parameters [9].

Vascular occlusions can be observed in LN and may relate to worse renal outcomes [10]. Acute thrombosis

\section{C) Biomed Central}


or chronic occlusive lesions in glomeruli and/or renal arterioles have also been described in patients with antiphospholipid syndrome (APS) $[11,12]$. Acute thrombosis in $\mathrm{LN}$, as detected with routine histology, is rarely observed, possibly because of its relatively sparse presence and the small size of tissue samples obtained with renal biopsy. Other chronic, nonspecific vascular occlusive histologic lesions may relate to older age and cardiovascular risk factors associated with arteriosclerotic disease, even in patients without aPLs (antiphospholipid antibodies) [13]. This type of chronic occlusive vascular lesions has been associated with a worse renal-function outcome. Immunohistochemical detection of CD $61^{+}$ intravascular platelets in SLE renal biopsies increases the sensitivity to detect microthrombosis and reveals a high prevalence of microthrombotic lesions in either aPL-negative or -positive LN patients [13]. Whether microthrombotic lesions are a consequence of renal inflammation or independently contribute to renal damage is unclear [10-12].

A link between activation of the complement system and aPL-induced thrombosis has been described in murine APS models [14,15]. In SLE patients with thrombosis and vascular aPL-related pathology, increased C4d deposition on platelets has been reported [16]. In SLE patients without aPL, C4d kidney deposition also correlates with thrombosis [17]. Therefore, complement activation might be a common mechanism of renal inflammation and thrombosis in patients with LN with or without aPL.

We undertook this study to investigate the potential relation between local complement activation, macrophagic infiltration, and renal microthrombosis, as well as their potential independent contribution to renal damage in a large series of SLE patients with proliferative nephritis. Our data provide evidence of the relation between these three processes but do not support an independent contribution of microthrombosis to renal damage.

\section{Materials and methods}

\section{Patients and kidney biopsies}

From a large cohort of SLE patients followed up at two University Hospitals between 1986 and 2010, we selected those with available kidney biopsy specimens to perform histologic and immunohistochemical studies. All patients fulfilled at least four of the American College of Rheumatology criteria for the diagnosis of SLE [18]. The study received approval by the Ethics Committee of Hospital 12 de Octubre. This study was performed on previously collected and filed pathology materials obtained after informed patient consent. Kidney biopsies had been performed for diagnostic purposes in patients with proteinuria higher than $500 \mathrm{mg} /$ day, abnormal urinary sediment, or elevated serum creatinine level. We considered that clinicopathologic correlations could be independently analyzed in different episodes, and therefore, biopsies from different episodes of the same patient were included when available. Kidney histology was evaluated and classified according to the ISN/RPS classification [19] by a pathologist who was blinded to patients' clinical and IHC data. Hematoxylin-eosin and phosphotungstic acid-hematoxylin (PAS) stained sections were evaluated. The whole series included 86 patients. In total, 101 histologic samples were analyzed. Among them, we selected 65 (64\%) samples with proliferative nephritis (ISN/RPS types II, III, and IV) from 58 patients for further study. Their demographic, clinical, laboratory, and pathology characteristics before and at renal biopsy are detailed in Table 1 .

APS was diagnosed according to the Sapporo criteria [20]. Definite APS was considered if at least one of the following clinical and laboratory criteria was satisfied. Clinical criteria included the presence of either vascular thrombosis or pregnancy morbidity. Laboratory criteria included the presence of aPL on two or more occasions at least 6 weeks apart, as demonstrated by one or more of the following: IgG and/or IgM anticardiolipin (aCL) antibodies in moderate or high titer and lupus anticoagulant (LA) activity. LA was detected after updated guidelines of the Subcommittee for the Standardization of Lupus Anticoagulant of the International Society of Thrombosis and Haemostasis [21], whereas aCLs were detected with enzyme-linked immunosorbent assay (ELISA) by following the manufacturer's instructions (Quanta Lite ACA IgG III and IgM III; Inova Diagnostics Inc, San Diego, CA, USA).

The following demographic data were recorded: sex, age, age at SLE diagnosis, age at renal disease, and time from kidney biopsy to the end of follow-up. Clinical and laboratory SLE data, including the disease-activity index SLEDAI [22], cardiovascular risk factors (high blood pressure (HBP), diabetes, hypercholesterolemia and/or hypertriglyceridemia, smoking, and hormonal contraception), APS criteria, and previous therapy were recorded.

Renal manifestations at biopsy and during the followup, specific therapy, response and time to response, and relapse and time to relapse were analyzed. Renal manifestations included HBP, renal failure defined as serum creatinine $\geq 1.5 \mathrm{mg} / \mathrm{dl}$ and/or creatinine clearance $\leq 65$ $\mathrm{ml} / \mathrm{min}$, 24-hour proteinuria, hematuria, leukocyturia, and cellular casts. Complete clinical response to therapy was defined by 24 hours of proteinuria lower than 500 $\mathrm{mg}$, normal urine sediment, and normal renal function (serum creatinine, $<1.5 \mathrm{mg} / \mathrm{dl}$, and creatinine clearance, $>75 \mathrm{ml} / \mathrm{min}$ ). Partial response to treatment was defined by improvement in all these parameters not reaching complete-response criteria. The presence of aPL (LA, IgG, or IgM aCL) and APS criteria before and after kidney disease was also recorded. 
Table 1 Demographic, clinical, and laboratory characteristics of SLE patients with proliferative nephritis

\begin{tabular}{|c|c|}
\hline & $\begin{array}{l}\text { Patients ( } n=58) \\
n \text { (\% or range) }\end{array}$ \\
\hline Sex: F/M & $54 / 4(93 / 7)$ \\
\hline Mean age (years) & $39 \pm 12(22-75)$ \\
\hline Mean age at SLE diagnosis (years) & $26 \pm 11(8-66)$ \\
\hline Mean age at nephritis (years) & $29 \pm 12(8-73)$ \\
\hline Mean duration of follow-up (months) & $97(1-273)$ \\
\hline Cardiovascular risk factors & $35(58)$ \\
\hline Positive aPL & $31(53.4)$ \\
\hline APS & $8(14.8)$ \\
\hline ANA $(+)$ & $58(100)$ \\
\hline a-DNA (+) & $49(84.5)$ \\
\hline $\mathrm{a}-\mathrm{Ro}(+)$ & $21(42.9)$ \\
\hline $\mathrm{a}-\mathrm{Sm}(+)$ & $16(33.3)$ \\
\hline a-RNP (+) & $11(22.9)$ \\
\hline Low complement levels & $52(91.2)$ \\
\hline \multicolumn{2}{|l|}{ Treatment before first renal biopsy } \\
\hline Antiaggregation & $20 / 65(31)$ \\
\hline Oral anticoagulation & $2 / 65(3.1)$ \\
\hline Glucocorticoids & $50 / 65(77)$ \\
\hline$\leq 7.5 \mathrm{mg} / \mathrm{d}$ prednisone & $42 \%$ \\
\hline $\begin{array}{l}<7.5 \text { to } 30 \mathrm{mg} / \mathrm{d} \\
\text { prednisone }\end{array}$ & $43 \%$ \\
\hline $\begin{array}{l}>30 \text { to } 60 \mathrm{mg} / \mathrm{d} \\
\text { prednisone }\end{array}$ & $10 \%$ \\
\hline$>1 \mathrm{mg} / \mathrm{kg} / \mathrm{d}$ prednisone & $5 \%$ \\
\hline Azathioprine & $13 / 65(20)$ \\
\hline Antimalarials & 20/65 (31) \\
\hline \multicolumn{2}{|l|}{ ISN/RPS nephritis classification: } \\
\hline Type ॥ & $2 / 65$ (3) \\
\hline Type III-A & $13 / 65(20)$ \\
\hline Type III-A/C & $4 / 65(6.1)$ \\
\hline Type III-A + V & $2 / 65(3)$ \\
\hline Type IV-SA & 10/65 (15.4) \\
\hline Type IV-SA/C & $4 / 65(6.1)$ \\
\hline Type IV-GA & 23/65 (35.4) \\
\hline Type IV-GA/C & $5 / 65(7.7)$ \\
\hline Type IV-GA/C + V & $2 / 65(3)$ \\
\hline 24 hours proteinuria $(\mathrm{mg})^{a}$ & $\begin{array}{l}3,355.1 \pm 3,372.3(230- \\
19,700)\end{array}$ \\
\hline Hematuria $(+)^{a}$ & $56(86.2)$ \\
\hline Leukocyturia $(+)^{a}$ & $52(80)$ \\
\hline Cellular casts $(+)^{a}$ & $42(64.6)$ \\
\hline Mean serum creatinine $(\mathrm{mg} / \mathrm{dl})^{\mathrm{a}}$ & $1.1 \pm 0.5(0.4-3.4)$ \\
\hline Mean creatinine clearance $(\mathrm{ml} / \mathrm{min})^{a}$ & $91.8 \pm 44.4(25-289)$ \\
\hline Renal failure $^{a}$ & $17(26.2)$ \\
\hline $\mathrm{HBP}^{\mathrm{a}}$ & $35(53.8)$ \\
\hline SLEDAI ${ }^{a}$ & $20.4(4-36)$ \\
\hline Response to treatment & $50(83.3)$ \\
\hline Mean time of response (months) & $15 \pm 19(1-101)$ \\
\hline
\end{tabular}

Cardiovascular risk factors include high blood pressure (HBP), diabetes, hypercholesterolemia and/or hypertriglyceridemia, smoking, and hormonal

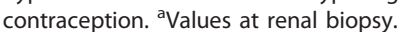

Immunohistochemical detection of CD61-positive platelet microthrombi, CD68-positive macrophages, and activated complement factor $\mathrm{C} 4 \mathrm{~d}$

Immunohistochemical studies were performed on paraffin-embedded kidney sections. Immunostaining with either monoclonal mouse anti-human CD68 (CD68, clone KP1; DakoCytomation Denmark A/S, Glostrup, Denmark), monoclonal mouse anti-human gpIIIa (CD61, sz21; Immunotech, Marseille, France), or polyclonal rabbit anti-human C4d (C4dpAb; Biomedica Medizinprodukte GmbH \& Co KG, Vienna, Austria) were performed. Renal sections from patients with primary thrombotic microangiopathy (TMA) were used as positive controls for CD61. Renal sections from a normal kidney were used as negative controls.

Sections were deparaffinized and pretreated with 10 $\mu \mathrm{g} / \mathrm{ml}$ proteinase K (P6556; Sigma-Aldrich Quimica SA, Madrid, Spain) in the case of CD61 detection, or boiled in $1 \mathrm{~m} M$ EDTA or citrate buffer $10 \mathrm{~m} M$, pH 6, for CD68 and C4d detection, respectively. The slides were incubated overnight at $4^{\circ} \mathrm{C}$ with primary antibodies. Immunohistochemical staining was performed with a peroxidase avidin-biotin complex technique (SK-4100; Vector Laboratories Inc., Burlingame, CA, USA). Diaminobenzidine was used as chromogen substrate, and sections were counterstained with hematoxylin.

Glomerular and extraglomerular CD68 and C4d staining was quantified by using the public domain imageprocessing program, Image J software [23]. In brief, the percentage of stained area in 10 glomeruli and 10 extraglomerular areas randomly selected from each sample was calculated. Two blinded and independent observers analyzed all slides.

\section{Statistical analysis}

The associations between categoric variables were tested by using the $\chi^{2}$ or Fisher Exact test, where appropriate. The odds ratios (ORs) with the corresponding 95\% confidence intervals (95\% CIs) were calculated. For continuous variables, the comparisons were carried out by using the $t$ test for two independent samples. A Spearman rank correlation was used to detect correlations among different study parameters. $P$ values less than 0.05 were considered significant. The analysis was performed by using advanced SPSS software version 15.

\section{Results}

Histologic and IHC detection of microthrombotic lesions, macrophagic infiltration, and C4d deposition in kidney biopsies

In healthy, histologically normal kidney sections used as controls for IHC, CD61-positive platelet aggregates were not detected (Figure 1a). CD61-positive microthrombi were detected in $52 \%$ of the proliferative $\mathrm{LN}$ tissues 

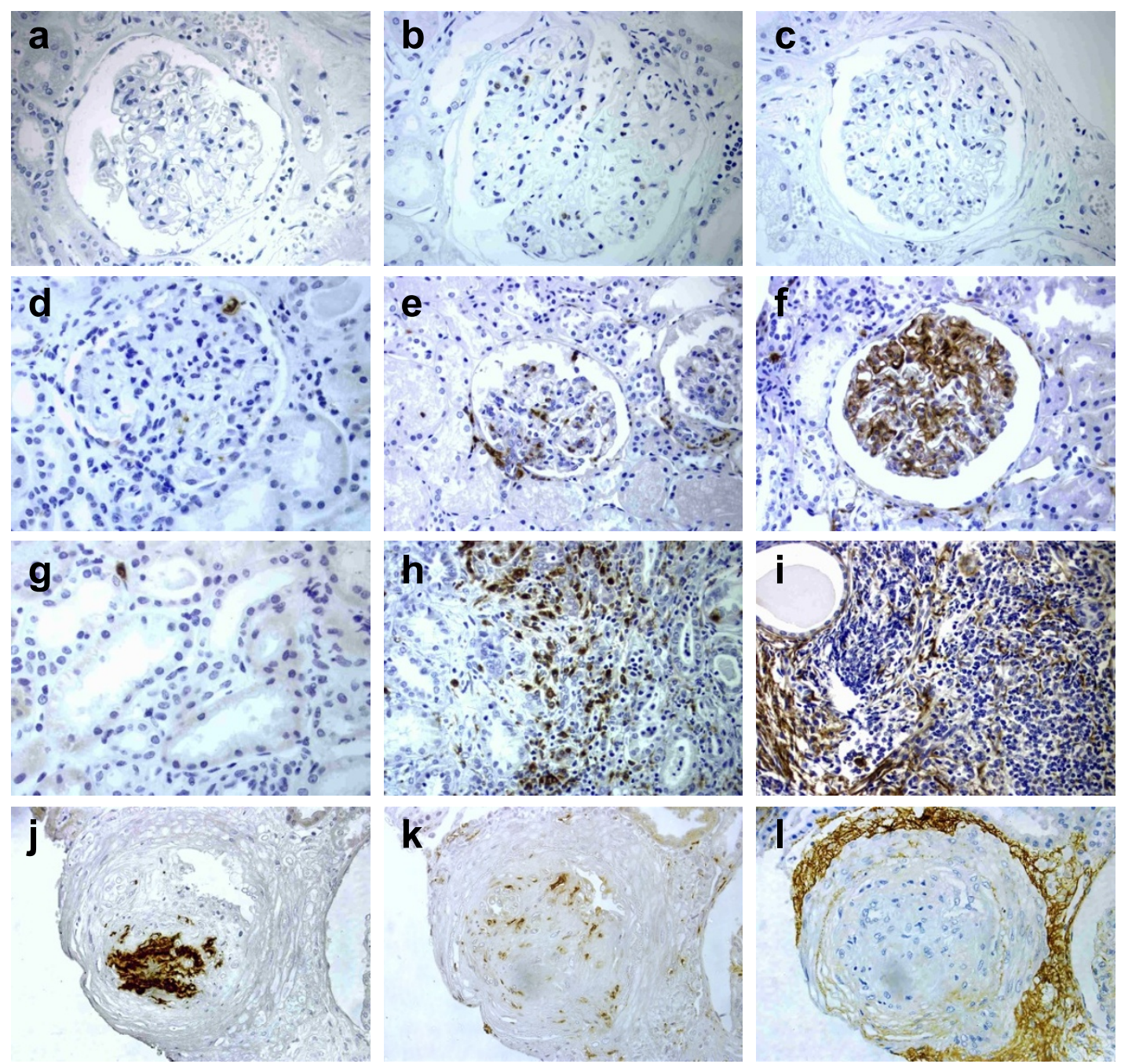

Figure 1 Immunohistochemical detection of platelet microthrombi lesions, macrophagic infiltration, and activated complement deposition in kidney biopsies. CD61 (left), CD68 (middle), and C4d (right) antigens were detected with immunoperoxidase (brown) in serial sections of healthy kidney (a through $\mathbf{c}$ ) and SLE nephritis tissues (d through I). SLE glomerular (d through $\mathbf{f}$ ) or extraglomerular ( $\mathbf{g}$ through $\mathbf{i}$ ) markers are shown. Positive CD61 microthrombi (j), CD68 infiltration (k), and C4d perivascular deposition (l) were detected. Sections were counterstained with hematoxylin. Original magnification, $\times 400$.

(79\% in glomerular and $62 \%$ in extraglomerular vessels)

(Figure 1d, g, j).

CD68-positive macrophages were identified in the mesangial areas of both normal (Figure 1b) and lupus glomeruli (Figure 1e), as well as in extraglomerular areas (Figure $1 \mathrm{~h}$ ). The density of CD68-positive macrophages in both glomerular and extraglomerular areas was greatly increased in lupus patients. The mean stained area was $2.37 \% \pm 3.02 \%$ and $0.72 \% \pm 0.98 \%$ in glomerular and extraglomerular regions of lupus sections, respectively, compared with $0.0004 \% \pm 0.0005 \%$ and $0.0003 \% \pm 0.0007 \%$ in normal kidney.

C4d deposition was undetectable in normal kidney sections (Figure 1c), whereas it was detected in most
SLE biopsies, in either glomerular (78\%) or extraglomerular (86\%) regions (Figure 1f, i). The mean C4d-stained glomerular and extraglomerular areas were $2.76 \% \pm$ $3.73 \%$ and $1.04 \% \pm 1.32 \%$, respectively. The main extraglomerular pattern was diffuse linear C4d deposition along peritubular capillaries (98\%), although some focal arteriolar C4d staining was also found in interstitial vessels (19\%) (Figure 1l).

\section{Clinical and laboratory correlations of platelet} aggregates, macrophage infiltration, and C4d deposition Patients with glomerular CD61-positive microthrombi had significantly higher glomerular $(P=0.03)$ macrophage infiltration. C4d extraglomerular deposition 
positively correlated with extraglomerular macrophage infiltration $(r=0.4 ; P=0.004)$, but mean C4d deposition was similar in patients with or without CD61-positive microthrombi.

The presence of platelet aggregates was significantly higher in patients with positive aPL (62\% versus $42 \%$; OR, 4.4; CI, 1.5 to $12.8 ; P=0.005$ ), but it was similar in patient groups with or without definite APS or with or without previous cardiovascular risk factors. No correlations were found between microthrombosis and SLE or renal clinical data, including positive anti-dsDNA antibodies, low complement levels, SLEDAI, 24-hour proteinuria, serum creatinine, creatinine clearance, or the presence of hematuria, leukocyturia, cellular casts, HBP, or renal failure.

Both glomerular and extraglomerular macrophagic infiltrations positively correlated with SLE manifestations. Glomerular macrophagic infiltration correlated with SLEDAI $(r=0.5 ; P<0.001)$ and was significantly higher in patients with positive anti-dsDNA antibodies $(P<0.001)$ or low complement levels $(P<0.001)$ at biopsy. Regarding renal manifestations, glomerular macrophagic infiltration positively correlated with 24hour proteinuria $(r=0.4 ; P=0.002)$ and was associated with the presence of microhematuria $(P<0.001)$, and cellular casts $(P=0.001)$. Extraglomerular macrophage infiltration correlated with SLEDAI $(r=0.3 ; P=0.01)$ but was not associated with the presence of anti-dsDNA antibodies or low complement levels. Regarding renal manifestations, extraglomerular macrophage infiltration correlated with 24-hour proteinuria $(r=0.4 ; P=0.001)$ but not with other analytic parameters. No correlation was found between glomerular or extraglomerular macrophage infiltration and renal function defined by creatinine clearance at biopsy.

Extraglomerular C4d deposition was significantly higher in patients with positive anti-dsDNA antibodies $(P=0.01)$ and correlated with SLEDAI $(r=0.4 ; P=$ $0.003)$ and 24 -hour proteinuria $(r=0.3 ; P=0.03)$. No differences in extraglomerular $\mathrm{C} 4 \mathrm{~d}$ deposition were found when we considered other clinical or laboratory parameters of renal function and SLE activity. Glomerular C4d deposition did not show any specific trend stratified by all clinical and laboratory variables. Clinical and laboratory correlations of platelet aggregates, macrophage infiltration, and C4d deposition are detailed in Table 2.

As initial therapy for $\mathrm{LN}$, all patients received high doses of steroids ( $\geq 1 \mathrm{mg} / \mathrm{kg} /$ day) as well as one of the following immunosuppressive drugs: cyclophosphamide (79\%), mycophenolate mofetil (17.7\%), or azathioprine (1.6\%). In addition, $54.2 \%$ received aspirin, and $5.1 \%$, oral anticoagulants. Most patients $(77 \%)$ had been treated with steroids before LN development for other manifestations at variable doses (Table 1). Twenty patients were treated with low-dose aspirin, and two patients were taking oral anticoagulation before LN development. In most patients treated with aspirin, indication was positive for LA and/or aCL antibodies $(n=$ 12). Some patients received aspirin for HBP. The two patients receiving oral anticoagulation had previous venous or arterial thrombosis. Different groups of patients stratified by aspirin or steroid dose did not show any trend toward a different expression of LN or platelet aggregates incidence, or differences in the longterm outcomes. Fifty (83.3\%) patients responded to treatment, and the mean time to partial or complete response was of 15.2 months (range, 1 to 101 months). To analyze the potential long-term effect of immunohistochemical findings on clinical and renal outcomes, we selected only patients homogeneously treated with intravenous cyclophosphamide according to the NIH protocol after excluding repeated episodes of LN [24]. In brief, induction therapy consisted of six monthly boluses of intravenous cyclophosphamide ( 0.5 to $1 \mathrm{~g}$ per square meter, further adjusted by leukocyte count) and glucocorticoids. After 6 months, patients were treated with intravenous cyclophosphamide boluses every 3 months and for at least 12 months after remission or stability. Maintenance therapy was variable and, according to clinical practice, included azathioprine, mycophenolate mofetil, or antimalarials with glucocorticoids. Taking into account only those patients $(n=43)$ who had received the same induction treatment, we did not found significant correlations between the presence of $\mathrm{CD} 1^{+}$microthrombi, macrophagic infiltration, or C4d deposition, and clinical outcomes including percentage of response to therapy, mean time to response, percentage of relapse, and long-term renal function.

\section{Discussion}

These data show that renal microthrombosis is highly prevalent in LN, affecting half of the patients with proliferative LN. It is more prevalent in patients with aPL, consistent with previous reports [13]. Moreover, microthrombosis correlates with higher macrophagic infiltration as a marker of inflammatory activity but not with C4d deposition. However, only macrophagic infiltration showed a correlation with SLE renal activity (proteinuria and active sediment), and neither the presence of CD61 ${ }^{+}$microthrombi nor C4d deposition correlated with $\mathrm{LN}$ severity or outcome. Although the mechanisms of thrombosis may be different, previous studies point to complement activation and inflammation as common mechanisms in LN- and aPL-associated vascular pathology. In APS, a "two hits" theory has been proposed, in which the presence of aPL would lead to thrombophilia through endothelial cell, platelet, and monocyte 
Table 2 Clinical and laboratory associations of CD61-positive microthrombi, CD68-positive macrophage infiltration, and C4d deposition

\begin{tabular}{|c|c|c|c|c|c|c|c|}
\hline & & \multicolumn{2}{|c|}{ CD61 microthrombi } & \multicolumn{2}{|c|}{$\mathrm{CD} 8^{+}$infiltration } & \multicolumn{2}{|c|}{ C4d deposition } \\
\hline & & + & - & Glomerular & Extraglomerular & Glomerular & Extraglomerular \\
\hline SLEDAI & & $20.5 \pm 6.9$ & $20.3 \pm 6.6$ & $r=0.5^{a}$ & $r=0.3^{a}$ & $r=-0.1$ & $r=0.4^{\mathrm{a}}$ \\
\hline \multirow[t]{2}{*}{$\mathrm{aPL}$} & + & $69 \%$ & $33 \%$ & $1.9 \pm 1.9$ & $1 \pm 1.3$ & $2.6 \pm 2.9$ & $0.9 \pm 1.4$ \\
\hline & - & $31 \%$ & $67 \%$ & $2.1 \pm 3.1$ & $0.4 \pm 0.6$ & $2.9 \pm 4.7$ & $1 \pm 1.2$ \\
\hline \multirow[t]{2}{*}{ anti-dsDNA } & + & $91 \%$ & $74 \%$ & $2.8 \pm 3.2^{a}$ & $0.8 \pm 1$ & $2.4 \pm 2.9$ & $1.2 \pm 1.4^{a}$ \\
\hline & - & $9 \%$ & $26 \%$ & $0.6 \pm 0.7$ & $0.5 \pm 0.8$ & $3.8 \pm 6$ & $0.5 \pm 0.5$ \\
\hline \multirow[t]{2}{*}{ Low complement } & + & $94 \%$ & $87 \%$ & $2.6 \pm 3.1^{a}$ & $0.7 \pm 1$ & $2.4 \pm 2.9$ & $1.1 \pm 1.4$ \\
\hline & - & $6 \%$ & $13 \%$ & $0.5 \pm 0.5$ & $0.9 \pm 0.9$ & $5.4 \pm 8$ & $0.8 \pm 0.5$ \\
\hline 24-hour proteinuria (g) & & $3.2 \pm 3.1$ & $3.6 \pm 3.6$ & $r=0.4^{a}$ & $r=0.4^{a}$ & $r=0.1$ & $r=0.3^{a}$ \\
\hline \multirow[t]{2}{*}{ Hematuria } & + & $88 \%$ & $84 \%$ & $2.7 \pm 3.2^{\mathrm{a}}$ & $0.8 \pm 0.9$ & $2.7 \pm 3.9$ & $1.1 \pm 1.4$ \\
\hline & - & $12 \%$ & $16 \%$ & $0.6 \pm 0.7$ & $0.6 \pm 1.4$ & $2.9 \pm 2.9$ & $0.5 \pm 0.6$ \\
\hline \multirow[t]{2}{*}{ Leukocyturia } & + & $76.50 \%$ & $84 \%$ & $2.7 \pm 3.2^{a}$ & $0.7 \pm 0.9$ & $2.7 \pm 3.6$ & $1.1 \pm 1.4$ \\
\hline & - & $23.50 \%$ & $16 \%$ & $1.3 \pm 1.5$ & $0.7 \pm 1.2$ & $2.8 \pm 4.5$ & $0.8 \pm 1$ \\
\hline \multirow[t]{2}{*}{ Cellular casts } & + & $62 \%$ & $68 \%$ & $3.1 \pm 3.5^{a}$ & $0.8 \pm 0.8$ & $3.1 \pm 4.2$ & $1.1 \pm 1.2$ \\
\hline & - & $38 \%$ & $32 \%$ & $1.1 \pm 1.3$ & $0.7 \pm 1.3$ & $2.1 \pm 2.7$ & $0.9 \pm 1.6$ \\
\hline Creatinine clearance & & $97.9 \pm 50.2$ & $84.3 \pm 35.6$ & $r=-0.01$ & $r=-0.2$ & $r=0.1$ & $r=-0.1$ \\
\hline \multirow[t]{2}{*}{ Response to treatment } & + & $81 \%$ & $95 \%$ & $3.1 \pm 3.5$ & $0.8 \pm 0.9$ & $2.9 \pm 4.2$ & $1.2 \pm 1.5$ \\
\hline & - & $19 \%$ & $5 \%$ & $2.2 \pm 1.4$ & $1.3 \pm 1.7$ & $1.9 \pm 1.5$ & $0.9 \pm 0.4$ \\
\hline Mean time to response & & $25.1 \pm 27.9$ & $8.8 \pm 10.8$ & $r=-0.15$ & $r=-0.26$ & $r=-0.17$ & $r=-0.05$ \\
\hline \multirow[t]{2}{*}{ LN relapse } & + & $33 \%$ & $45 \%$ & $2.8 \pm 3.3$ & $0.6 \pm 0.7$ & $1.9 \pm 2.9$ & $1.1 \pm 1.1$ \\
\hline & - & $67 \%$ & $55 \%$ & $3.4 \pm 4.4$ & $0.7 \pm 0.8$ & $2.9 \pm 3.5$ & $1.4 \pm 1.9$ \\
\hline \multirow[t]{2}{*}{ Renal failure at 1 year } & + & $17.40 \%$ & $15 \%$ & $3.2 \pm 3.6$ & $0.8 \pm 0.9$ & $2.9 \pm 4.2$ & $1.3 \pm 1.6$ \\
\hline & - & $82.60 \%$ & $85 \%$ & $1.9 \pm 2.1$ & $1.5 \pm 1.6$ & $1.3 \pm 1.7$ & $1.2 \pm 0.7$ \\
\hline \multirow[t]{2}{*}{ Renal failure at last visit } & + & $20.80 \%$ & $30 \%$ & $3.3 \pm 3.7$ & $0.9 \pm 1$ & $3 \pm 4.4$ & $1.3 \pm 1.6$ \\
\hline & - & $79.20 \%$ & $70 \%$ & $2.1 \pm 1.9$ & $1 \pm 1.4$ & $1.5 \pm 1.7$ & $1 \pm 0.7$ \\
\hline
\end{tabular}

${ }^{\mathrm{a}} P<0.05$.

activation ("first hit"), and a "second hit" related to inflammation (that is, Toll-like receptors and complement activation, in response to microbial agents, might synergize and result in clotting events [25]. Our data link inflammatory infiltration and thrombosis in LN but are less clear regarding the relation of complement activation and thrombosis.

Several studies point to the involvement of complement in the pathogenesis of APS. In animal models, complement factors $\mathrm{C} 3$ and $\mathrm{C} 5$ are essential in aPLmediated pathology [15]. In these models, endothelial cell activation and inflammatory cell infiltration around blood vessels are observed in placental lesions, suggesting that complications of pregnancy are primarily due to inflammation [14]. In humans, a few studies also point to complement activation in aPL-mediated thrombosis [26-28]. Sera from patients with positive aPL enhance complement fixation on platelets, which is associated with arterial thrombosis [16]. Platelet-associated C4d has been reported in $18 \%$ of patients with SLE, particularly in those with aPL [29]. In addition, hypocomplementemia and increased plasma levels of anaphylotoxins
C3a and C4a have been described in primary APS [26]. However, a direct correlation between increased levels of anaphylotoxins and clinical thrombosis has not been demonstrated $[26,28]$.

Specifically in LN, immune-mediated vascular injury may predispose to platelet accumulation and in situ complement activation. Intense glomerular $\mathrm{C} 4 \mathrm{~d}$ deposition has been previously found associated with renal microthrombi in LN patients with or without aPL $[15,28]$. However, because both processes may be associated with proliferative $\mathrm{LN}$ and higher activity indexes, this may be an indirect association [26]. We have specifically analyzed patients with proliferative LN and considered macrophage infiltration as an additional marker of inflammatory activity. Our data do not demonstrate a direct relation between C4d deposition and microthrombosis. Instead, C4d deposition correlated with the intensity of macrophagic infiltration, which in turn was associated with microthrombosis. Deposition of C4d in peritubular capillaries reflected SLE activity, consistent with previous reports [30,31]. Neither C4d nor microthrombi were directly related to the severity or outcome of LN. 
The detection of CD61 intravascular platelets with IHC is far more sensitive to acute microthrombi in patients with LN compared with routine histologic methods. Thrombi detected with regular histology might have a different impact on renal outcomes but are rarely observed. Clinical observations support that TMA in APS or SLE nephritis has an important impact on renal function and requires specific therapy. However, TMA may occur independent of SLE nephritis, and its prevalence associated with LN is very low. Only two cases had microthrombi detected by histology in our series, precluding analyses of the clinical and subclinical (immunohistochemical) correlations in LN. Our data do not support any difference in renal manifestations and outcomes at 6 and 12 months, and further follow-up after therapy in patients with IHC detected CD61-positive microthrombi. The retrospective design of our study limits the interpretation of results regarding clinical correlations and prognosis. Microthrombi detected with IHC may have a lower impact on renal function and outcome than do larger histologic microthrombi. Longitudinal prospective studies, including patients with $\mathrm{LN}$ and repeated biopsies after induction treatment, will help us to better define the real significance of this kind of histologic and IHC lesion.

Macrophagic infiltration was the best marker of renal impairment at kidney biopsy, consistent with previous studies [32]. Glomerular and interstitial macrophage infiltration is a feature of the more aggressive forms of LN and the individual variable that best correlates with clinical parameters, including SLE activity and renal manifestations. We found a correlation with activity measures, including the level of proteinuria and active sediment, but not with renal function at biopsy or follow-up. A previous study showed that the persistence of glomerular and extraglomerular macrophagic infiltrates after therapy correlates with long-term renal-function outcomes (doubling of serum creatinine and end-stage renal disease) [32]. However, neither these nor our data demonstrates predictive value for the degree of macrophage infiltration at first biopsy and renal-function outcomes.

\section{Conclusions}

In summary, our results show a relation between renal microthrombi and local inflammatory cells infiltration in patients with LN. Renal macrophagic infiltration was the best marker of SLE and renal clinical activity, whereas microthrombi or C4d deposition did not have a direct correlate with severity or prognosis in $\mathrm{LN}$.

\section{Abbreviations}

aCL: anticardiolipin antibodies; aPLs: antiphospholipid antibodies; APS antiphospholipid syndrome; ELISA: enzyme-linked immunosorbent assay; HBP: high blood pressure; IHC: immunohistochemistry; ISN/RPS: international society of nephrology/renal pathology society; LA: lupus anticoagulant; LN: lupus nephritis; MCP-1: monocyte chemoattractant protein-1; $\mathrm{NIH}$ : national institute of health; OR: odds ratio; PAS: phosphotungstic acid-hematoxylin; SLE: systemic lupus erythematosus; TGF-beta 1: transforming growth factorbeta 1; TMA: thombotic microangiopathy; SLEDAl: systemic lupus erythematosus disease activity index.

\section{Acknowledgements}

The authors thank Dr. Gabriel Usera for his help with kidney histopathology. This study was supported by Fondo de Investigación Sanitaria (PI06/90374) and RIER (Red de Inflamación y Enfermedades Reumáticas RD08/0075).

\section{Author details}

${ }^{1}$ Instituto de Investigación Hospital 12 de Octubre (i+12), Avenida de Córdoba sn, 28041 Madrid, Spain. ${ }^{2}$ Servicio de Anatomía Patológica, Hospital 12 de Octubre, Avenida de Córdoba sn, 28041 Madrid, Spain. ${ }^{3}$ Servicio de Reumatología, Hospital 12 de Octubre, Avenida de Córdoba sn, 28041 Madrid, Spain. ${ }^{4}$ Servicio de Reumatología, Hospital Regional Universitario Carlos Haya, Avenida Carlos Haya sn, 29010 Málaga, Spain. ${ }^{5}$ Unidad de Investigación de la Fundación Española de Reumatología, Sociedad Española de Reumatología, Calle Marqués del Duero 5, 1², 28001 Madrid, Spain. ${ }^{6}$ Servicio de Anatomía Patológica, Hospital Regional Universitario Carlos Haya, Avenida Carlos Haya sn, 29010 Málaga, Spain.

\section{Authors' contributions}

EG and BS carried out IHC analyses. OT, IG, and ML carried out histologic studies at Hospital 12 de Octubre (OT) and Hospital Regional Carlos Haya $(\mathrm{IG}, \mathrm{ML})$, respectively. MPM, MG, MCO, and AFN participated in collecting and analyzing clinical data, both at Hospital 12 de Octubre (MPM, MG) and at Hospital Regional Carlos Haya (MCO, AF), respectively. EL participated in the design and statistical analysis. JLP and MG participated in the conception and design of the study, coordination, and analysis of data. All authors participated in drafting and revising the manuscript and read and approved its final version.

\section{Competing interests}

The authors declare that they have no competing interests.

Received: 17 October 2011 Revised: 11 May 2012

Accepted: 28 May 2012 Published: 28 May 2012

\section{References}

1. Cameron JS: Lupus nephritis. J Am Soc Nephrol 1999, 10:413-424

2. Austin HA III, Boumpas DT, Vaughan EM, Balow JE: High-risk features of lupus nephritis: importance of race and clinical and histological factors in 166 patients. Nephrol Dial Transplant 1995, 10:1620-1628.

3. Esdaile JM, Federgreen W, Quintal H, Suissa S, Hayslett JP, Kashgarian M: Predictors of one year outcome in lupus nephritis: the importance of renal biopsy. Q J Med 1991, 81:907-918

4. Yang N, Isbel NM, Nikolic-Paterson DJ, Li Y, Ye R, Atkins RC, Lan HY: Local macrophage proliferation in human glomerulonephritis. Kidney Int 1998 54:143-151.

5. Takemura T, Yoshioka K, Murakami K, Akano N, Okada M, Aya N, Maki S: Cellular localization of inflammatory cytokines in human glomerulonephritis. Virchows Arch 1994, 424:459-464.

6. Grandaliano G, Gesualdo L, Ranieri E, Monno R, Montinaro V, Marra F, Schena FP: Monocyte chemotactic peptide-1 expression in acute and chronic human nephritides: a pathogenetic role in interstitial monocytes recruitment. J Am Soc Nephrol 1996, 7:906-913.

7. Wada T, Yokoyama H, Su SB, Mukaida N, Iwano M, Dohi K, Takahashi Y, Sasaki T, Furuichi K, Segawa C, Hisada Y, Ohta S, Takasawa K, Kobayashi K, Matsushima K: Monitoring urinary levels of monocyte chemotactic and activating factor reflects disease activity of lupus nephritis. Kidney Int 1996, 49:761-767.

8. Wagrowska-Danilewicz M, Stasikowska O, Danilewicz M: Correlative insights into immunoexpression of monocyte chemoattractant protein-1, transforming growth factor beta-1 and CD68+ cells in lupus nephritis. Pol J Pathol 2005, 56:115-120.

9. Hill GS, Delahousse M, Nochy D, Tomkiewicz E, Rémy P, Mignon F, Méry JP: A new morphologic index for the evaluation of renal biopsies in lupus nephritis. Kidney Int 2000, 58:1160-1173. 
10. Descombes E, Droz D, Drouet L, Grünfeld JP, Lesavre P: Renal vascular lesions in lupus nephritis. Medicine (Baltimore) 1997, 76:355-368.

11. Nochy D, Daugas E, Droz D, Beaufils H, Grünfeld JP, Piette JC, Bariety J, Hill G: The intrarenal vascular lesions associated with primary antiphospholipid syndrome. J Am Soc Nephrol 1999, 10:507-18,

12. Tektonidou MG, Sotsiou F, Nakopoulou L, Vlachoyiannopoulos PG, Moutsopoulos HM: Antiphospholipid syndrome nephropathy in patients with systemic lupus erythematosus and antiphospholipid antibodies: prevalence, clinical associations, and long-term outcome. Arthritis Rheum 2004, 50:2569-2579.

13. Galindo M, Gonzalo E, Martinez-Vidal MP, Montes S, Redondo N, Santiago B, Loza E, Pablos JL: Immunohistochemical detection of intravascular platelet microthrombi in patients with lupus nephritis and antiphospholipid antibodies. Rheumatology 2009, 48:1003-1007.

14. Girardi G, Berman J, Redecha P, Spruce L, Thurman JM, Kraus D, Hollmann TJ, Casali P, Caroll MC, Wetsel RA, Lambris JD, Holers VM, Salmon JE: Complement C5a receptors and neutrophils mediate fetal injury in the antiphospholipid syndrome. J Clin Invest 2003, 112:1644-1654.

15. Pierangeli SS, Girardi G, Vega-Ostertag M, Liu X, Espinola RG, Salmon J: Requirement of activation of complement C 3 and C5 for antiphospholipid antibody-mediated thrombophilia. Arthritis Rheum 2005, 52:2120-2124.

16. Peerschke El, Yin W, Alpert DR, Roubey RA, Salmon JE, Ghebrehiwet B: Serum complement activation on heterologous platelets is associated with arterial thrombosis in patients with systemic lupus erythematosus and antiphospholipid antibodies. Lupus 2009, 18:530-538.

17. Cohen D, Koopmans $M$, Kremer Hovinga ICL, Berger SP, Roos van Groningen M, Steup-Beekman GM, de Heer E, Bruijn JA, Bajema IM: Potential for glomerular C4d as an indicator of thrombotic microangiopathy in lupus nephritis. Arthritis Rheum 2008, 58:2460-2469.

18. Tan EM, Cohen AS, Fries JF, Masi AT, McShane DJ, Rothfield NF, Schaller JG, Talal N, Winchester RJ: The 1982 revised criteria for the classification of systemic lupus erythematosus. Arthritis Rheum 1982, 25:1271-1277.

19. Weening JJ, D'Agati VD, Schwartz MM, Seshan SV, Alpers CE, Appel GB, Balow JE, Bruijn JA, Cook T, Ferrario F, Fogo AB, Ginzler EM, Hebert L, Hill G, Hill P, Jennette JC, Kong NC, Lesavre P, Lockshin M, Looi LM, Makino H, Moura LA, Nagata M: The classification of glomerulonephritis in systemic lupus erythematosus revisited. J Am Soc Nephrol 2004, 150:2 41-250.

20. Wilson WA, Gharavi AE, Koike T, Lockshin MD, Branch DW, Piette JC, Brey R, Derksen R, Harris EN, Hughes GR, Triplett DA, Khamashta MA: International consensus statement on preliminary classification criteria for definite antiphospholipid syndrome: report of an international workshop. Arthritis Rheum 1999, 42:1309-1311.

21. Pengo V, Tripodi A, Reber G, Rand JH, Ortel TL, Galli M, De Groot PG: Subcommittee on Lupus Anticoagulant/Antiphospholipid Antibody of the Scientific and Standardisation Committee of the International Society on Thrombosis and Haemostasis: Update of the guidelines for lupus anticoagulant detection. J Thromb Haemost 2009, 7:1737-1740.

22. Bombardier C, Gladman DD, Urowitz MB, Caron D, Chang CH: Derivation of the SLEDAl: a disease activity index for lupus patients: the Committee on Prognosis Studies in SLE. Arthritis Rheum 1992, 35:630-640.

23. Image J: Image processing and analysis in Java. [http://rsb.info.nih.gov/ij].

24. Austin HA, Klippel JH, Balow JE, le Riche NG, Steinberg AD, Plotz PH, Decker JL: Therapy of lupus nephritis: controlled trial of prednisone and cytotoxic drugs. N Engl J Med 1986, 314:614-619.

25. Leroyer AS, Anfosso F, Lacroix R, Sabatier F, Simoncini S, Njock SM, Jourde N, Brunet P, Camoin-Jau L, Sampol J, Dignat-George F: Endothelialderived microparticles: biological conveyors at the crossroad of inflammation, thrombosis and angiogenesis. Thromb Haemost 2010, 104:456-463.

26. Distelmaier K, Adlbrecht C, Jakowitsch J, Winkler S, Dunkler D, Gerner C, Wagner $\mathrm{O}$, Lang IM, Kubicek M: Local complement activation triggers neutrophil recruitment to the site of thrombus formation in acute myocardial infarction. Thromb Haemost 2009, 102:564-572.

27. Oku K, Atsumi T, Bohgaki M, Amengual O, Kataoka H, Horita T, Yasuda S, Koike T: Complement activation in patients with primary antiphospholipid syndrome. Ann Rheum Dis 2009, 68:1030-1035.

28. Shen Y, Chen XW, Sun CY, Dai M, Yan YC, Yang CD: Association between anti-beta2 glycoprotein I antibodies and renal glomerular C4d deposition in lupus nephritis patients with glomerular microthrombosis: a prospective study of 155 cases. Lupus 2010, 19:1195-1203.

29. Navratil JS, Manzi S, Kao AH, Krishnaswami S, Liu CC, Ruffing MJ, Shaw PS, Nilson AC, Dryden ER, Johnson JJ, Ahearn JM: Platelet C4d is highly specific for systemic lupus erythematosus. Arthritis Rheum 2006, 54:670-674.

30. Kim SH, Jeong HJ: Glomerular C4d deposition indicates in situ classic complement pathway activation, but is not a marker for lupus nephritis activity. Yonsei Med J 2003, 44:75-80.

31. Li SJ, Liu ZH, Zen CH, Wang QW, Wang Y, Li LS: Peritubular capillary C4d deposition in lupus nephritis different from antibody-mediated renal rejection. Lupus 2007, 16:875-880.

32. Hill GS, Delahousse M, Nochy D, Rémy P, Mignon F, Méry JP, Bariéty J: Predictive power of the second renal biopsy in lupus nephritis: significance of macrophages. Kidney Int 2001, 59:304-316.

\section{doi:10.1186/ar3856}

Cite this article as: Gonzalo et al:: Clinicopathologic correlations of renal microthrombosis and inflammatory markers in proliferative lupus nephritis. Arthritis Research \& Therapy 2012 14:R126.

\section{Submit your next manuscript to BioMed Central and take full advantage of:}

- Convenient online submission

- Thorough peer review

- No space constraints or color figure charges

- Immediate publication on acceptance

- Inclusion in PubMed, CAS, Scopus and Google Scholar

- Research which is freely available for redistribution

Submit your manuscript at www.biomedcentral.com/submit
C) Biomed Central 